\title{
Group B Streptococcus detection in pregnant women: comparison of qPCR assay, culture, and the Xpert GBS rapid test
}

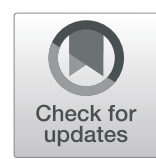

Laura L. Vieira', Amanda V. Perez ${ }^{2 *}$, Monique M. Machado ${ }^{1}$, Michele L. Kayser ${ }^{1}$, Daniela V. Vettori ${ }^{1}$, Ana Paula Alegretti ${ }^{3}$, Charles F. Ferreira', Janete Vettorazzi ${ }^{1}$ and Edimárlei G. Valério ${ }^{1}$

\begin{abstract}
Background: Group B Streptococcus (GBS) is one of the most important causative agents of neonatal sepsis. As administration of prophylactic antibiotics during labor can prevent GBS infection, routine screening for this bacterium in prenatal care before the onset of labor is recommended. However, many women present in labor without having undergone such testing during antenatal care, and the turnaround time of detection methods is insufficient for results to be obtained before delivery.

Methods: Vaginal and anorectal specimens were collected from 270 pregnant women. Each sample was tested by Xpert GBS, qPCR, and culture for GBS detection.

Results: The overall prevalence of maternal GBS colonization was $30.7 \%$ according to Xpert GBS, $51.1 \%$ according to $\mathrm{QPCR}$, and $14.3 \%$ according to cultures. Considering the GPCR method as the reference, the Xpert GBS had a sensitivity of $53 \%$ and specificity of $93 \%$. Positive Xpert GBS results were correlated to marital status (married or cohabitating) and with prematurity as a cause of neonatal hospitalization. Positive cultures were related with ischemic-hypoxic encephalopathy requiring therapeutic hypothermia.

Conclusions: Combined enrichment/qPCR and the Xpert GBS rapid test found a high prevalence of GBS colonization. The Xpert GBS technique gives faster results and could be useful for evaluating mothers who present without antenatal GBS screening results and are at risk of preterm labor, thus allowing institution of prophylactic antibiotic therapy.
\end{abstract}

Keywords: Group B Streptococcus, Streptococcus agalactiae, Xpert GBS, Real-time polymerase chain reaction, Antenatal care

\section{Background}

Group B Streptococcus (GBS) is a gram-positive bacterium associated with the colonization of human body's mucous membranes. GBS is one of the most important causative agents of neonatal sepsis, which can be prevented by administration of prophylactic antibiotics during labor. Women can be transiently, intermittently, or persistently colonized by GBS in their vaginal or anorectal mucosae [1]. A prevention strategy based on bacterial screening

\footnotetext{
* Correspondence: amandavperez@gmail.com

${ }^{2}$ Serviço de Obstetrícia e Ginecologia, Hospital de Clínicas de Porto Alegre,

Rua Ramiro Barcelos, 2350/1124, Santa Cecília, Porto Alegre, RS CEP:

90035-903, Brazil

Full list of author information is available at the end of the article
}

and intrapartum antimicrobial prophylaxis in those pregnant women identified as carriers has led to a reduction in the incidence of neonatal diseases attributable to GBS [2]. The U.S. Centers for Disease Control and Prevention (CDC) [3] recommend routine screening for GBS as an integral part of antenatal care. Ideally, this should be done at a gestational age of 35 to 37 weeks, or earlier in women at risk of premature labor.

Routine GBS screening is done by polymerase chain reaction (PCR)-based tests and cultures. A 2011 study that evaluated a combination of enrichment culture and PCR versus conventional cultures at Hospital de Clínicas de Porto Alegre (HCPA), a tertiary care hospital in Southern Brazil [4], found that enrichment culture/PCR

(c) The Author(s). 2019 Open Access This article is distributed under the terms of the Creative Commons Attribution 4.0 International License (http://creativecommons.org/licenses/by/4.0/), which permits unrestricted use, distribution, and 
had $87 \%$ specificity, with a positive predictive value of $59 \%$ and a negative predictive value of $100 \%$. Since 2015, enrichment culture with real-time polymerase chain reaction (qPCR) has become the standard method for GBS detection at HCPA [4-6]. However, these methods usually take around $48-72 \mathrm{~h}$ to complete, which has prompted the search for a more rapid test, especially to support urgent decisionmaking regarding administration of antibiotic prophylaxis.

The Xpert $^{\circ}$ GBS (Cepheid) is a rapid test based on qPCR technology whereby rectal and vaginal swabs are collected and a result is obtained in approximately 50 min. This method is commercially available in Brazil and has demonstrated high sensitivity for GBS detection in other studies $[7,8]$.

Considering that many women in Brazil present in labor without having undergone GBS screening during antenatal care, and that many women at risk of preterm labor are admitted to maternity units before GBS screening can be performed on an outpatient basis, the turnaround time of conventional GBS detection methods is too slow for results to be obtained before delivery. Within this context, the present study was designed to evaluate the diagnostic accuracy of the Xpert GBS rapid test and compare it with that of combined enrichment/ qPCR (currently used for GBS screening at HCPA) and with the conventional vaginal/rectal discharge culture method.

\section{Methods}

This prospective study was carried out between March and September 2017. Pregnant women who presented for medical appointments at the outpatient, antenatal, and labor and delivery units of the HCPA (Porto Alegre Clinic Hospital) Department of Obstetrics and Gynecology were recruited. The study (number: 2016-0560) was approved by the Research Ethics Committee of Gynecology and Obstetrics Research and Postgraduate Group (GPPG-GO) and conducted in accordance with the provisions of the Declaration of Helsinki. All patients provided written informed consent prior to enrollment. In case of participants under 18 years of age, the guardian also signed the consent form. The inclusion criterion was gestational age $\geq 24$ weeks, while the exclusion criterion was any use of antibiotics in the 30 days preceding enrollment.

Among 300 enrolled women, 30 were excluded: 5 refused to participate, 10 had already undergone GBS screening and received their results at the time of study inclusion, and 15 had used antibiotics in the last 30 days (Fig. 1). Thus, the final sample comprised 270 women.

Three vaginal and rectal swabs (one sample for each screening method - Xpert GBS, qPCR, and culture) were collected from each patient and immediately stored in Stuart transport medium, according to CDC recommendations. The swabs collected for qPCR were sent to the HCPA microbiology and molecular biology laboratories; the culture swabs were sent to an outside laboratory (Endocrimeta $\left.{ }^{\circ}\right)$; and the Xpert GBS samples were analyzed

Assessed for elegibility $(N=300)$

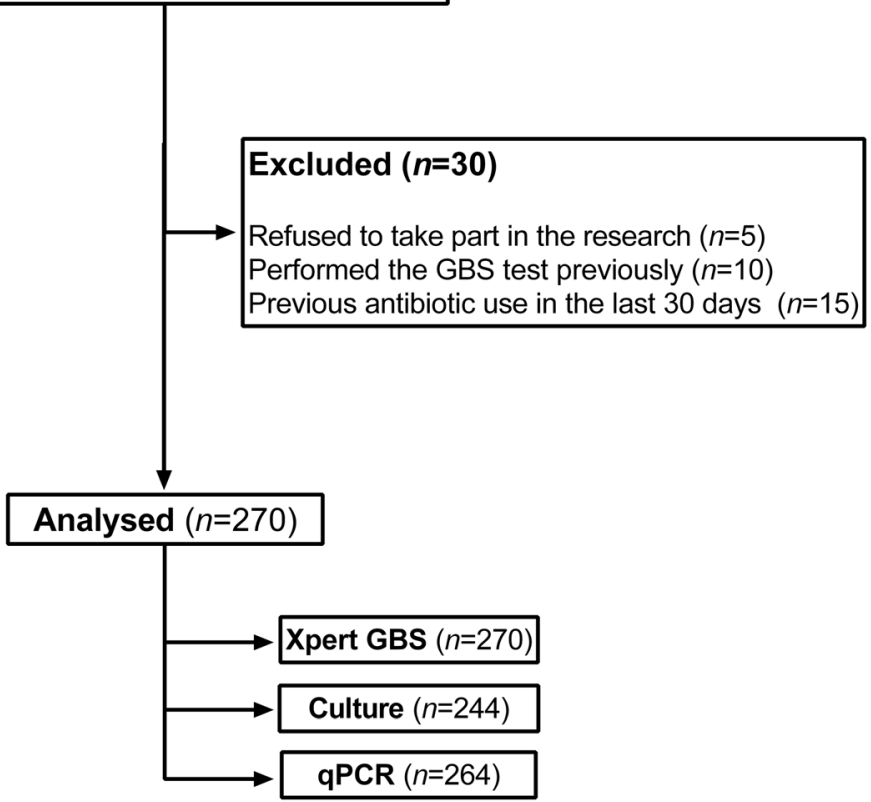

Fig. 1 Patiente selection flowchart 
on specific equipment provided by Cepheid. All samples were sent for evaluation within $24 \mathrm{~h}$ of collection.

\section{Xpert $^{\circledast}$ GBS (Cepheid)}

The collected swab was transferred to the designated chamber of the Xpert GBS cartridge, which was loaded into a Cepheid GeneXpert device, as recommended by the manufacturer. A trained physician performed all Xpert GBS assays. The result could be negative or positive based on the detection of the target gene sequence adjacent to the GBS $c f b$ gene, as defined by the GeneXpert software. Xpert GBS performs automation and integration of sample lysis, amplification and purification of nucleic acids, and detection of the target sequence using qPCR. The total assay runtime was around $50 \mathrm{~min}$.

\section{GBS culture}

The collected swab was inoculated on blood agar plates and incubated at $37^{\circ} \mathrm{C}$ for $48 \mathrm{~h}$ in a microbiological incubator. After incubation, the plates were inspected for the presence of beta-hemolytic colonies. If there was any suspicion of beta-hemolytic plaque growth after $48 \mathrm{~h}$, plaques were reincubated for another $24 \mathrm{~h}$ and inspected again. Betahemolytic colonies whose morphology were consistent with GBS were subcultured and CAMP-tested [9]. CAMPpositive colonies were deemed presumably positive for GBS.

\section{Real-time polymerase chain reaction (qPCR)}

Sample preparation and DNA (deoxyribonucleic acid) extraction.

The swabs were incubated for 18 to $24 \mathrm{~h}$ into Todd Hewitt selective medium containing gentamicin and nalidixic acid. After centrifugation of the broth, the precipitate was washed with 1X PBS (phosphate-buffered saline) solution $(\mathrm{pH}=7.2)$ and centrifuged again. Then, the precipitate was washed with $1 \mathrm{X}$ Tris-EDTA (TE) buffer (10 mM Tris- $\mathrm{HCl}, 0.1 \mathrm{mM}$ EDTA, $\mathrm{pH}=7.5)$, and DNA extracted by thermal lysis. The thermal lysis protocol was performed using TE solution for $15 \mathrm{~min}$ at $100^{\circ} \mathrm{C}$ followed by $15 \mathrm{~min}$ at $-80^{\circ} \mathrm{C}$ to lyse bacterial cell walls. The quality and quantity of DNA extracted from samples were estimated spectrophotometrically in a Nanodrop ND-1000 system (Thermo Fisher Scientific, USA), at $260 \mathrm{~nm}$ (A260) and $280 \mathrm{~nm}$ (A280) absorbance, with the sample diluted to $5 \mathrm{ng} / \mu \mathrm{L}$.

\section{Real-time polymerase chain reaction}

For the qPCR, we used the $c f b$ gene region that encodes the CAMP factor present in GBS. The primers used were $5^{\prime}-$ TTT CAC CAG CTG TAT TAG AAG TA-3' and 5'GTT CCC TGA ACA TTA TCT TTG AT-3'. For internal control, a synthetic single-chain DNA (5'-ATC GCT GAT CCG GCC ACA TAT CGC GTT TAT GCG AGG TCG GGT GGG CGG GTC GTT AGT TTC GTT TTG GGC
CTA CGT GGC CTT TGT CAC CGA-3') was used to detect amplification inhibition in all samples using the primers 5'-ATC GCT GAT CCG GCC ACA-3' and 5'TCG GTG ACA AAG GCC ACG TA-3'.

The amplification reagents were prepared as follows: Platinum $^{\circ} \mathrm{SYBR}^{\circ}$ Green (Invitrogen) concentrated mix $6.25 \mu \mathrm{L}$, SBG primers $1.25 \mu \mathrm{L}$, ROX 1:50 $0.25 \mu \mathrm{L}$, and DNAse- and RNAse-free water $2.5 \mu \mathrm{L} ; 0.5 \mu \mathrm{L}$ of internal control (IC) solution and $0.75 \mu \mathrm{L}$ of primers were added to the IC tube.

The extracted DNA solution was added to $10 \mu \mathrm{L}$ of amplification reagents. Amplification and fluorescent detection were measured by qPCR in a 7500 Real-Time PCR System (Applied Biosystems). The amplification was performed with one cycle at $50^{\circ} \mathrm{C}$ for $2 \mathrm{~min}$ for DNA polymerase activation, followed by one cycle at $95^{\circ} \mathrm{C}$ for $10 \mathrm{~min}$ for initial denaturation, than 40 cycles at $95^{\circ} \mathrm{C}$ for $15 \mathrm{~s}$ and $60^{\circ} \mathrm{C}$ for $1 \mathrm{~min}$ for amplification, followed by two cycles at $95^{\circ} \mathrm{C}$ for $15 \mathrm{~s}$ and $60^{\circ} \mathrm{C}$ for 15 $\mathrm{s}$ for fluorescence detection and melting temperature (Tm) measurement. Samples are considered positive when the amplification curve is detected and the Tm is in the acceptable range (GBS $\mathrm{Tm} 76-78^{\circ} \mathrm{C}$ and IC $\mathrm{Tm}$ $82-84^{\circ} \mathrm{C}$ ). The negative control should not have an amplification curve for the GBS target, while the positive control should be positive for the two targets tested. To ensure high sensitivity in the PCR, the cutoff point was set at a threshold cycle value of $C_{t}=40[10,11]$.

\section{Statistical analysis and sample size}

Sample size was calculated in WinPEPI Version 11.63, based on the findings of a previous study [4]. Considering a $16 \%$ prevalence of GBS positivity with the goldstandard method (culture) and $95 \%$ power to detect a $5 \%$ difference in prevalence of a positive result, with an estimated $10 \%$ attrition rate, the final sample size required was 230 participants.

Regarding the data processing, we used a database double entry, and review were performed using the SPSS, version 18.0. [SPSS Inc. Released 2009. PASW Statistics for Windows, Version 18.0. Chicago: SPSS Inc.]. Symmetric data was expressed as mean and standard error of mean $( \pm$ SEM), or by median and interquartile range [Percentiles 25th-75th, P25-P75]. The ShapiroWilk test was used to determine the normality of data distribution. Categorical variables were described as absolute $(\mathrm{n})$ and relative $(\mathrm{n} \%)$ frequencies.

Agreement between assays was determined using the kappa and Cronbach's alpha coefficients. The sensitivity, specificity, negative predictive value, and positive predictive value of the tests were evaluated in accordance with STARD (Standards for Reporting of Diagnostic Accuracy) initiative recommendations. 
Spearman's $\rho$ coefficients were estimated for obstetric characteristics and GBS positivity.

The level of significance was set at 5\% for all analysis.

\section{Results}

The maternal characteristics and main neonatal outcomes are listed in Tables 1 and 2. The median [P25-P75] maternal age was 29 [22.0-35.0] years, 39.3\% were nulliparous, $72.6 \%$ were white, and $82.6 \%$ were single or not living with a partner. Women with a gestational age $<35$ weeks and any risk of preterm labor represented $48.7 \%$ of the sample. Considering fetal characteristics and neonatal outcomes, most were not premature (66.3\%) and, among them, were categorized as moderate to late preterm (86.9\%). In addition, most newborns had no fetal malformations (96.1\%). A rate of $2.5 \%$ of neonatal death was observed, with median [P25-P75] Apgar score, 5-min, of 9.0 [9.0-10.0]. Most newborns (62.4\%) were not admitted to the Neonatal Intensive Care Unit (NICU).

Xpert GBS testing was performed in samples from 270 women; 75 (27.8\%) were positive, 169 (62.6\%) were negative, $1(0.4 \%)$ was inconclusive, $21(7.8 \%)$ yielded errors, and $4(1.5 \%)$ had no result available, as shown in Table 3. The percentage of errors may be justified by a known and reported problem with a specific batch of cartridges, while four samples were lost due to a power outage (no result).

Only the positive and negative results were included in the analysis. Considering these results alone, the overall prevalence of maternal GBS colonization was $51.1 \%$ according to $\mathrm{qPCR}, 30.7 \%$ according to Xpert GBS, and $14.3 \%$ according to cultures (Table 3 ).

We compared the performance of the three tests considering valid results alone (Table 4). A total of 239 women were screened with both the Xpert GBS and qPCR. GBS colonization was detected in 124 (51.9\%) with qPCR versus 74 (31.0\%) with the Xpert GBS. Considering qPCR as the reference, the Xpert GBS had a sensitivity of $53.2 \%$ and a specificity of $93.0 \%$. The positive predictive value was $89.2 \%$, and the negative predictive value was $64.8 \%$. The kappa coefficient between the two techniques indicates moderate agreement $(\mathrm{kappa}=0.46)$, with apparent low sensitivity and high specificity for the rapid test.

A total of 220 women were screened with both the Xpert GBS and culture methods with valid results. GBS colonization was detected in 66 patients $(30.0 \%)$ by the Xpert GBS versus $34(15.5 \%)$ with the culture method (Table 4). Considering culture as the gold standard, the Xpert GBS had a sensitivity of $61.8 \%$ and a specificity of $75.8 \%$. The positive predictive value was $31.8 \%$, and the negative predictive value was $91.6 \%$. The kappa coefficient between the two techniques indicates fair agreement (kappa $=0.27$ ).

In this study, GBS colonization detected by qPCR was not related to maternal characteristics, such as age,
Table 1 Obstetric data of the women included in the study

\begin{tabular}{|c|c|}
\hline Variable & Total $(\boldsymbol{n}=270)$ \\
\hline Age (years), md [P25-75] & $29.0[22.0-35.0]$ \\
\hline \multicolumn{2}{|l|}{ Race/ethnicity, n (\%) } \\
\hline White & $196(72.6)$ \\
\hline Nonwhite & $74(27.4)$ \\
\hline \multicolumn{2}{|l|}{ Marital status, n (\%) } \\
\hline Single or not living with a partner & $223(82.6)$ \\
\hline Married or cohabitating & $47(17.4)$ \\
\hline \multicolumn{2}{|l|}{ Educational attainment, n (\%) } \\
\hline Incomplete primary education & $64(23.7)$ \\
\hline Completed primary education & $48(17.8)$ \\
\hline Incomplete secondary education & $38(14.1)$ \\
\hline Completed secondary education & $83(30.7)$ \\
\hline Incomplete higher education & $24(8.9)$ \\
\hline Completed higher education & $13(4.8)$ \\
\hline Gestational age at sampling (weeks), md [P25-75] & $35.0[32.7-36.1]$ \\
\hline Gestational age < 35 weeks (days), n (\%) & $131(48.7)$ \\
\hline Gestational age at birth (weeks), md [P25-75] & $38.6[36.4-39.5]$ \\
\hline \multicolumn{2}{|l|}{ Parity, n (\%) } \\
\hline Nulliparous & $106(39.3)$ \\
\hline Primiparous & $72(26.7)$ \\
\hline Multiparous & $92(34.1)$ \\
\hline Number of antenatal appointments, md [P25-75] & $8.0[5.0-11.0]$ \\
\hline \multicolumn{2}{|l|}{ Mode of delivery, $\mathrm{n}(\%)$} \\
\hline Cesarean & $134(49.6)$ \\
\hline Vaginal & $126(46.7)$ \\
\hline Missing & $10(3.7)$ \\
\hline \multicolumn{2}{|l|}{ Complications, n (\%) } \\
\hline Yes & $33(12.2)$ \\
\hline No & $227(84.1)$ \\
\hline Missing & $10(3.7)$ \\
\hline \multicolumn{2}{|l|}{ Type of complications, n (\%) } \\
\hline Uterine hypotonicity & $21(58.3)$ \\
\hline Chorioamnionitis & $6(16.7)$ \\
\hline Reintervention & $4(11.1)$ \\
\hline ICU admission & $2(5.6)$ \\
\hline Postpartum fever & $2(5.6)$ \\
\hline Endometritis & $1(2.8)$ \\
\hline \multicolumn{2}{|l|}{ Sample collection setting $-\mathrm{n}(\%)$} \\
\hline Inpatient & $103(38.1)$ \\
\hline Outpatient & $167(61.9)$ \\
\hline
\end{tabular}

$n$ absolute frequency, \% relative frequency, $m d$ median, $P 25-75$ interquartile range [percentiles 25 th-75th], ICU intensive care unit 
Table 2 Fetal characteristics and neonatal outcomes

\begin{tabular}{|c|c|}
\hline Variables & Total $(\boldsymbol{n}=282)^{a}$ \\
\hline \multicolumn{2}{|l|}{ Prematurity - n (\%) } \\
\hline Yes & $84(29.8)$ \\
\hline No & $187(66.3)$ \\
\hline Missing & $11(3.9)$ \\
\hline \multicolumn{2}{|l|}{ Preterm birth - n (\%) } \\
\hline Extremely preterm (GA $\leq 28$ weeks) & $4(4.8)$ \\
\hline Very preterm (GA 28-32 weeks) & $7(8.3)$ \\
\hline Moderate to late preterm (GA > 32-37 weeks) & $73(86.9)$ \\
\hline \multicolumn{2}{|l|}{ Fetal malformations - n (\%) } \\
\hline Yes & $11(3.9)$ \\
\hline No & $271(96.1)$ \\
\hline \multicolumn{2}{|l|}{ Birthweight - n (\%) } \\
\hline Extremely low $(\leq 999 \mathrm{~g})$ & $5(1.8)$ \\
\hline Very low (1000-1499 g) & $4(1.4)$ \\
\hline Low (1500-2499 g) & $67(23.8)$ \\
\hline Adequate ( $\geq 2500 \mathrm{~g}$ ) & $195(69.1)$ \\
\hline Missing & $11(3.9)$ \\
\hline \multicolumn{2}{|l|}{ Neonatal death - n (\%) } \\
\hline Yes & $7(2.5)$ \\
\hline No & $262(92.9)$ \\
\hline Fetal death & $2(0.7)$ \\
\hline Missing & $11(3.9)$ \\
\hline Apgar score, 5-min - md [P25-75] & $9.0[9.0-10.0]$ \\
\hline \multicolumn{2}{|l|}{ Neonatal asphyxia- $\mathrm{n}(\%)$} \\
\hline Yes & $17(6.1)$ \\
\hline No & $221(78.9)$ \\
\hline Missing & $42(15.0)$ \\
\hline \multicolumn{2}{|l|}{ NICU admission - n (\%) } \\
\hline Yes & $92(32.6)$ \\
\hline No & $176(62.4)$ \\
\hline Fetal death & $2(0.7)$ \\
\hline Missing & $12(4.3)$ \\
\hline \multicolumn{2}{|l|}{ Cause of NICU admission - n (\%) } \\
\hline Respiratory distress & $49(53.3)$ \\
\hline Jaundice & $20(21.7)$ \\
\hline Prematurity & $20(21.7)$ \\
\hline Sepsis & $19(20.7)$ \\
\hline Fetal malformation & $11(12.0)$ \\
\hline Congenital syphilis & $10(10.9)$ \\
\hline Hypoglycemia & $9(9.8)$ \\
\hline Low birthweight & $3(3.3)$ \\
\hline Maternal condition & $2(2.2)$ \\
\hline Cyanosis and hypertonia & $1(1.1)$ \\
\hline Workup of cutaneous lesions & $1(1.1)$ \\
\hline
\end{tabular}

Table 2 Fetal characteristics and neonatal outcomes (Continued)

\begin{tabular}{ll}
\hline Variables & Total $(\boldsymbol{n}=282)^{\mathrm{a}}$ \\
\hline Workup of urinary tract malformation & $1(1.1)$ \\
Ischemic-hypoxic encephalopathy & $1(1.1)$ \\
Causes of neonatal death - n (\%) & $5(71.4)$ \\
Fetal malformation & $2(28.6)$ \\
Extreme prematurity & \\
\hline $\begin{array}{l}n \text { absolute frequency, \% relative frequency, md median; interquartile range } \\
\text { [percentiles 25th-75th]; NICU Neonatal Intensive Care Unit; }{ }^{\text {an }} \mathbf{n}=282, \\
\text { including twins }\end{array}$
\end{tabular}

marital status, ethnicity, education attainment, and parity, nor with maternal or neonatal complications, such as chorioamnionitis and sepsis. Positive results with the Xpert GBS rapid test were correlated to marital status (married or cohabitating) and with preterm delivery as a cause of neonatal hospitalization. Finally, ischemic-hypoxic encephalopathy and need for therapeutic hypothermia were related with positive cultures (Table 5).

\section{Discussion}

The overall prevalence of GBS colonization varies depending on the studied population and the test used for screening. This variability may be related to various climatic, biological, sociocultural, geographic, and methodological determinants [12, 13]. In Brazil, prevalence has been reported to range from 9 to 36\% [13-15]. In one Brazilian study [14] that compared culture and PCR, only $9.5 \%$ of samples were positive for GBS by culture, while $32.6 \%$ were positive when using PCR methods. Our study population was restricted to patients of a public hospital that serves as a referral center for high-risk pregnancies, which may explain our finding of a much higher prevalence (51.1\%) than is usually reported in the literature, considering the GPCR method. In fact, this is one of the highest prevalence values ever reported among Brazilian women. In a 2011 study [4] conducted at the same hospital as the present investigation but using the conventional PCR agarose gel technique, the prevalence of GBS was $27.0 \%$-much lower than that found in the present study. However, this difference can be justified by the higher sensitivity of qPCR.

In a study [16] carried out among women in the Southeast region of Brazil, the prevalence of GBS by the culture method was around $18 \%$, although only vaginal samples were collected. In an Italian sample of pregnant women [17], about $20 \%$ were GBS-positive with the culture method. The prevalence of GBS by culture in the present study (14.3\%) was similar to the results of previous studies $[4,14,16]$. The low prevalence of GBS positivity by culture methods as compared to other modalities may be justified by issues of technical execution, as the culture technique does not always follow CDC recommendations [3], or 
Table 3 Results of antepartum GBS screening by qPCR, Xpert GBS, and culture

\begin{tabular}{lllll}
\hline Variable & Total $(\boldsymbol{n}=810)$ & qPCR $(n=270)$ & Xpert GBS $(n=270)$ & Culture $(n=270)$ \\
\hline Status $-\mathrm{n}(\%)$ & & & & $35(27.8)$ \\
$\quad$ Positive & $245(30.2)$ & $135(50.0)$ & $169(62.6)$ & $209(77.4)$ \\
Negative & $507(62.6)$ & $129(47.8)$ & $1(0.4)$ & $0(0.0)$ \\
Inconclusive & $1(0.0)$ & $0(0.0)$ & $21(7.8)$ & $0(0.0)$ \\
Error & $21(2.6)$ & $0(0.0)$ & $4(1.5)$ & $0(0.0)$ \\
No result & $4(0.5)$ & $0(0.0)$ & $0(0.0)$ & $26(9.6)$ \\
Not done & $32(4.0)$ & $6(2.2)$ & 244 & 244 \\
Valid results $-\mathrm{n}$ & 752 & 264 & $75(30.7)$ & $35(14.3)$ \\
Positive & $245(32.6)$ & $135(51.1)$ & $169(69.3)$ & $209(85.7)$ \\
Negative & $507(67.4)$ & $129(48.9)$ & & \\
\hline
\end{tabular}

$q P C R$ real-time polymerase chain reaction, $n$ absolute frequency, $\%$ relative frequency

perhaps because this method has a much lower sensitivity than PCR-based methods.

According to the CDC [3], cultures are the goldstandard method for GBS screening in pregnant women at 35-37 weeks of gestational age. The CDC guidelines also cite other laboratory tests for GBS detection, including PCR methods. PCR-based approaches are gaining a promising role in GBS detection, largely due to their higher sensitivity $[6,13,18,19]$. A European consensus statement noted that failure to treat GBS-positive mothers could lead to serious adverse neonatal outcomes. Thus, it seems reasonable to consider methods with higher sensitivity even if they are associated with more false-positive results.

On comparison of the Xpert GBS to qPCR, we found a high degree of agreement on negative results (93\% specificity), but only reasonable agreement on positive results ( $53 \%$ sensitivity). These discordant results can be justified by the higher sensitivity of the combined sample enrichment/qPCR method. As the maternal pathogen load that characterizes actual risk of neonatal infection is unknown, it is unclear whether a real need exists to increase the sensitivity of rapid tests or if their current parameters are sufficient to support clinical decision-making.

Considering culture as the gold standard, the Xpert GBS showed a sensitivity of $62 \%$ and a specificity of $76 \%$ in this study. According to Gavino [20], the sensitivity and specificity of the Xpert GBS were 95.8 and $64.5 \%$ respectively, while those of antenatal cultures were 83.3 and $80.6 \%$ respectively. Mueller [21] found a sensitivity of $85.7 \%$ and a specificity of $95.6 \%$ for the Xpert GBS compared to culture. These divergent results suggest that additional studies are needed to evaluate this method.

In a previous evaluation [17] of the performance of the Xpert GBS rapid test when performed intrapartum, 13.4\% of performed tests failed to yield a valid result on the first attempt (7.3\% erroneous, $4.4 \%$ invalid, and $1.6 \%$ yielded no result). Another study [22] reported an invalid result rate of $13.6 \%$, while Mueller [21] reported $13.4 \%$ after a 2 -h training session on thermocycler operation. In the present study,

Table 4 Pairwise comparisons between diagnostic tests used for GBS screening

\begin{tabular}{|c|c|c|c|c|c|c|c|}
\hline n (\%) & & Positive & Negative & Total & $\begin{array}{l}{ }^{\text {a }} \boldsymbol{p}- \\
\text { value }\end{array}$ & Kappa & $\begin{array}{l}\text { Cronbach's } \\
\text { a }\end{array}$ \\
\hline \multirow[t]{3}{*}{ Xpert GBS } & Positive & 66 (53.0) & $8(7.0)$ & $74(31.0)$ & \multirow[t]{3}{*}{$\leq 0.0001$} & \multirow[t]{3}{*}{0.456} & \multirow[t]{3}{*}{0.665} \\
\hline & Negative & $58(47.0)$ & $107(93.0)$ & $165(69.0)$ & & & \\
\hline & Total & $124(100.0)$ & $115(100.0)$ & $239(100.0)$ & & & \\
\hline \multirow[t]{4}{*}{ Culture } & Positive & $31(25.4)$ & $3(2.5)$ & $34(14.2)$ & \multirow[t]{4}{*}{$\leq 0.0001$} & \multirow[t]{4}{*}{0.226} & \multirow[t]{4}{*}{0.471} \\
\hline & Negative & $91(74.6)$ & 115 (97.5) & $206(85.8)$ & & & \\
\hline & Total & $122(100.0)$ & $118(100.0)$ & $240(100.0)$ & & & \\
\hline & & Xpert GBS & & & & & \\
\hline \multirow[t]{3}{*}{ Culture } & Positive & $21(31.8)$ & $13(8.4)$ & $34(15.5)$ & \multirow[t]{3}{*}{$\leq 0.0001$} & \multirow[t]{3}{*}{0.271} & \multirow[t]{3}{*}{0.447} \\
\hline & Negative & $45(68.2)$ & 141 (91.6) & $186(84.5)$ & & & \\
\hline & Total & $66(100.0)$ & $154(100.0)$ & $220(110.0)$ & & & \\
\hline
\end{tabular}

$n$ absolute frequency, \% relative frequency, $q P C R$ real-time polymerase chain reaction, $p$ statistical significance

${ }^{\mathrm{a}} \mathrm{Chi}$-square test with adjusted residual values 
Table 5 Correlations between obstetric characteristics and GBS positivity

\begin{tabular}{|c|c|c|c|c|c|c|}
\hline \multirow[t]{2}{*}{ Items } & \multicolumn{2}{|l|}{ Xpert GBS } & \multicolumn{2}{|l|}{$\mathrm{qPCR}$} & \multicolumn{2}{|l|}{ Culture } \\
\hline & Coefficient & ${ }^{a} p$-value & Coefficient & ${ }^{a} p$-value & Coefficient & ${ }^{a} p$-value \\
\hline Age & -0.075 & 0.242 & 0.036 & 0.561 & 0.047 & 0.464 \\
\hline Educational level & 0.013 & 0.837 & 0.039 & 0.531 & 0.065 & 0.314 \\
\hline Single or not living with a partner & -0.143 & 0.025 & -0.059 & 0.342 & -0.040 & 0.535 \\
\hline Black ethnicity & 0.094 & 0.141 & 0.054 & 0.385 & 0.037 & 0.562 \\
\hline Parity & -0.002 & 0.970 & 0.012 & 0.844 & -0.091 & 0.154 \\
\hline Maternal complications & -0.087 & 0.183 & -0.012 & 0.850 & 0.071 & 0.279 \\
\hline Chorioamnionitis & 0.027 & 0.680 & 0.047 & 0.456 & 0.008 & 0.906 \\
\hline Endometritis & -0.044 & 0.499 & 0.061 & 0.334 & -0.027 & 0.676 \\
\hline Intrapartum fever & 0.037 & 0.573 & -0.003 & 0.964 & 0.091 & 0.164 \\
\hline Neonatal complications & 0.095 & 0.146 & 0.009 & 0.888 & -0.002 & 0.971 \\
\hline NICU admission & -0.099 & 0.133 & 0.011 & 0.867 & -0.031 & 0.641 \\
\hline \multicolumn{7}{|l|}{ Cause of NICU admission } \\
\hline Sepsis & 0.035 & 0.761 & -0.053 & 0.629 & 0.061 & 0.587 \\
\hline Prematurity & 0.242 & 0.031 & -0.111 & 0.310 & -0.003 & 0.976 \\
\hline Respiratory distress & -0.101 & 0.371 & -0.028 & 0.800 & -0.153 & 0.172 \\
\hline Ischemic-hypoxic encephalopathy & 0.195 & 0.083 & 0.104 & 0.343 & 0.282 & 0.011 \\
\hline Hypothermia protocol & 0.097 & 0.139 & 0.061 & 0.334 & 0.156 & 0.017 \\
\hline
\end{tabular}

$q P C R$ real-time polymerase chain reaction; $\mathrm{n}$, absolute frequency, \% relative frequency, NICU Neonatal Intensive Care Unit, $p$ index of statistical significance ${ }^{a}$ Spearman correlations. Significance set at $5 \%$ for all analyses

$p$ value $<0,05$ has statistical significance

$90.4 \%$ of tests were valid; the remainder were $0.4 \%$ inconclusive, $7.8 \%$ erroneous, and $1.5 \%$ yielded no result. Although some of the errors found in this study may be justified by known problems with a batch of Xpert cartridges, the percentage of invalid tests is consistent with previous reports in the literature.

Positive GBS test results were not related to neonatal sepsis in this study. Considering that GBS infection can be very serious and affects approximately $2 \%$ of newborns whose mothers are colonized, a larger sample would almost certainly be needed to demonstrate this association; more probably, the absence of association found in this sample suggests that intrapartum antibiotic prophylaxis is effectively preventing neonatal infection by GBS.

\section{Conclusion}

We found a high prevalence of GBS colonization with PCR-based tests. According to qPCR with prior sample enrichment, $51.1 \%$ of samples were positive for GBS. This is among the highest prevalence values ever reported in Brazilian women; additional studies using the same technique are warranted to confirm these findings.

On the other hand, in this study the Xpert GBS test detected a prevalence of GBS colonization among Brazilian women similar to that found in the literature (around 30\%). We conclude that the Xpert GBS test may be an option for rapid diagnosis, especially in women at risk for preterm labor and women presenting in labor who did not undergo prenatal GBS testing. This would allow initiation of appropriate antibiotic therapy, as well as reduce hospital costs and prevent development of bacterial resistance to antimicrobials. Furthermore, this would protect asymptomatic newborns whose mothers do not have GBS results available from undergoing unnecessary investigations.

Bacterial cultures for GBS detection, which are currently considered the gold-standard method by the CDC, may be replaced by more sensitive and specific methods, such as different PCR-based techniques.

Several factors interfere with the results of the different tests available for GBS detection. Additional studies are needed to compare the performance of these tests, as well as to compare their findings with clinical outcomes.

\section{Abbreviations}

CDC: Centers for Disease Control and Prevention; DNA: Deoxyribonucleic acid; GBS: Group B Streptococcus; HCPA: Hospital de Clínicas de Porto Alegre; IC: Internal control; PBS: Phosphate-buffered saline; PCR: Polymerase chain reaction; QPCR: Real-time polymerase chain reaction; STARD: Standards for reporting of diagnostic accuracy; Tm: Melting temperature

\section{Acknowledgements}

Not applicable.

Competing of interest

The authors declare that they have no competing interests. 


\section{Authors' contributions}

JV, EGV and LLV conceived/designed the study and worked on data collection. LLV, AVP, MLK and MMM worked on data collection. LLV, JV, EGV, CFF, DW, AVP and APA carried out the initial analyses, drafted the initial manuscript, and critically reviewed and revised the manuscript. All authors read and approved the final manuscript as submitted.

\section{Funding}

This work was supported by Fundo de Incentivo à Pesquisa e Ensino, Hospital de Clínicas de Porto Alegre (FIPE/HCPA) and Programa de Apoio à PósGraduação, Universidade Federal do Rio Grande do Sul (PROAP/UFRGS). The financial aid was for the purchase of GBS quick test kits. The sponsoring institution did not participate in the study design, data collection or article writing.

\section{Availability of data and materials}

The datasets used and/or analysed during the current study are available from the corresponding author on reasonable request.

\section{Ethics approval and consent to participate}

The study was approved by the Research Ethics Committee of Hospital de Clínicas de Porto Alegre (research and Postgraduation Group - GPPG/HCPA, number: 2016-0560) and conducted in accordance with the provisions of the Declaration of Helsinki. All patients provided written informed consent prior to enrollment. In case of participants under 18 years of age, the guardian also signed the consent form.

\section{Consent for publication}

Not applicable.

\section{Author details}

'Department of Gynaecology and Obstetrics Postgraduation Program in Health Sciences: Gynaecology and Obstetrics (PPGGO), School of Medicine (FAMED), Clinical Hospital of Porto Alegre (HCPA). Federal University of Rio Grande do Sul (UFRGS), Porto Alegre, RS, Brazil. ${ }^{2}$ Serviço de Obstetrícia e Ginecologia, Hospital de Clínicas de Porto Alegre, Rua Ramiro Barcelos, 2350/ 1124, Santa Cecília, Porto Alegre, RS CEP: 90035-903, Brazil. ${ }^{3}$ Department of Molecular Biology, Clinical Hospital of Porto Alegre (HCPA), Porto Alegre, RS, Brazil.

Received: 16 July 2019 Accepted: 16 December 2019

Published online: 30 December 2019

\section{References}

1. Kwatra G, Cunnington MC, Merrall E, et al. Prevalence of maternal colonisation with group B streptococcus: a systematic review and metaanalysis. Lancet Infect Dis. 2016;16:1076-84.

2. Verani JR, Schrag SJ. Group B streptococcal disease in infants: progress in prevention and continued challenges. Clin Perinatol. 2010;37:375-92.

3. Verani JR, McGee L, Schrag SJ, et al. Prevention of perinatal group B streptococcal disease--revised guidelines from CDC, 2010. MMWR Recomm Rep. 2010;59:1-36.

4. de Paris F, Machado AB, Gheno TC, et al. Grouping B Streptococcus detection: comparison of PCR assay and culture as a screening method for pregnant women. Braz J Infect Dis. 2011;15:323-7.

5. Ke D, Ménard C, Picard FJ, et al. Development of conventional and real-time PCR assays for the rapid detection of group B streptococci. Clin Chem. 2000; 46:324-31.

6. Munari FM, De-Paris F, Salton GD, et al. A combined enrichment/polymerase chain reaction based method for the routine screening of Streptococcus agalactiae in pregnant women. Braz J Microbiol. 2011;43:253-60.

7. El Helali N, Nguyen JC, Ly A, et al. Diagnostic accuracy of a rapid real-time polymerase chain reaction assay for universal intrapartum group B streptococcus screening. Clin Infect Dis. 2009:49:417-23.

8. Edwards RK, Novak-Weekley SM, Koty PP, et al. Rapid group B streptococci screening using a real-time polymerase chain reaction assay. Obstet Gynecol. 2008;111:1335-41.

9. Phillips EA, Tapsall JW, Smith DD. Rapid tube CAMP test for identification of Streptococcus agalactiae (Lancefield group B). J Clin Microbiol. 1980;12:135-7.
10. Yeung SW, Cheung PT, Chau SL, et al. Evaluation of an in-house real-time polymerase chain reaction method to identify group B streptococcus colonization in pregnancy. J Obstet Gynaecol Res. 2015;41:1357-62.

11. Meehan M, Cafferkey M, Corcoran S, et al. Real-time polymerase chain reaction and culture in the diagnosis of invasive group B streptococcal disease in infants: a retrospective study. Eur J Clin Microbiol Infect Dis. 2015; 34:2413-20.

12. Sharmila V, Joseph NM, Arun Babu T, et al. Genital tract group B streptococcal colonization in pregnant women: a south Indian perspective. J Infect Dev Ctries. 2011;5:592-5.

13. Wollheim C, Sperhacke RD, Fontana SKR, et al. Group B Streptococcus detection in pregnant women via culture and PCR methods. Rev Soc Bras Med Trop. 2017:50:179-83.

14. Castellano-Filho DS, da Silva VL, Nascimento TC, et al. Detection of group B Streptococcus in Brazilian pregnant women and antimicrobial susceptibility patterns. Braz J Microbiol. 2010;41:1047-55.

15. Melo SCCS, Costa AB, Silva FTRD, et al. Prevalence of Streptococcus agalactiae colonization in pregnant women from the 18th health region of Paraná state. Rev Inst Med Trop Sao Paulo. 2018;60:e2.

16. Zusman AS, Baltimore RS, Fonseca SNS. Prevalence of maternal group B streptococcal colonization and related risk factors in a Brazilian population. Braz J Infect Dis. 2006; 10:242-6.

17. Picchiassi E, Coata G, Babucci G, et al. Intrapartum test for detection of group B Streptococcus colonization during labor. J Matern Fetal Neonatal Med. 2017;31:3293-300.

18. Feuerschuette OHM, Silveira SK, Cancelier ACL, et al. Diagnostic yield of realtime polymerase chain reaction in the diagnosis of intrapartum maternal rectovaginal colonization by group B Streptococcus: a systematic review with meta-analysis. Diagn Microbiol Infect Dis. 2018;91:99-104.

19. Di Renzo GC, Melin P, Berardi A, et al. Intrapartum GBS screening and antibiotic prophylaxis: a European consensus conference. J Matern Fetal Neonatal Med. 2015;28(7):766-82

20. Gavino M, Wang E. A comparison of a new rapid real-time polymerase chain reaction system to traditional culture in determining group $B$ streptococcus colonization. Am J Obstet Gynecol. 2007:197:388.

21. Mueller M, Henle A, Droz S, et al. Intrapartum detection of group B streptococci colonization by rapid PCR-test on labor ward. Eur J Obstet Gynecol Reprod Biol. 2014;176:137-41.

22. Plainvert $C$, El Alaoui F, Tazi A, et al. Intrapartum group B Streptococcus screening in the labor ward by Xpert ${ }^{\oplus}$ GBS real-time PCR. Eur J Clin Microbiol Infect Dis. 2018:37:265-70.

\section{Publisher's Note}

Springer Nature remains neutral with regard to jurisdictional claims in published maps and institutional affiliations.

Ready to submit your research? Choose BMC and benefit from:

- fast, convenient online submission

- thorough peer review by experienced researchers in your field

- rapid publication on acceptance

- support for research data, including large and complex data types

- gold Open Access which fosters wider collaboration and increased citations

- maximum visibility for your research: over $100 \mathrm{M}$ website views per year

At $\mathrm{BMC}$, research is always in progress.

Learn more biomedcentral.com/submissions 